\title{
Finding Trends in Human-Automation Interaction Research in Order to Formulate a Cognitive Automation Strategy for Final Assembly
}

\author{
Asa Fast-Berglund*, Sandra Mattsson, Lars-ola Bligard \\ Chalmers University, Horsalsvagen 7a, SE-41296 Gothenburg, Sweden
}

Received: August 17, 2016; Accepted: August 28, 2016; Published: August 30, 2016

*Corresponding author: Asa Fast-Berglund, Chalmers University, Horsalsvagen 7a, SE-41296 Gothenburg, Sweden, Tel: +46-317723686, Email: asa.fasth@chalmers.se

\begin{abstract}
This article presents a literature review within the area of Human-Automation-Interaction in order to find trends and central factors in recent HAI research. These factors will then be used in order to suggest a cognitive automation strategy for final assembly. Trends within final assembly is towards take individual aspects into account, choose an appropriate level of automation and investigate trust and joint-interaction factors. In addition, automation system processes should be made more transparent in order to keep the operator in the decision-loop.
\end{abstract}

Keywords: Human-Automation Interaction; Production; Assembly; Digitalization

\section{Introduction and Problem Area}

A prerequisite for the success of modern manufacturing companies is the ability to produce mass-customized products with many variants as effectively as possible. This demands a high degree of flexibility and re-configurability of the production system [1]. In these systems, human operators remain an invaluable resource, by virtue of being superior to robots at rapidly interpreting unplanned tasks and situations and handling flexibility and complexity [2-4]. Within manufacturing, assembly tasks are very important to consider since assembly of manufactured goods accounts for over 50 percent of total production time and 20 percent of the cost $[5,6]$. A challenge for final assembly is to find a strategy on how to improve and design a complex station."So far, no company in the world seems to have developed a clear vision as to how to design this humanmachine interface in terms of both higher competitiveness and better quality of work life" (p. 6 Fujimoto, et al. [7]). Although this was written in 1997 no new strategy or framework solving these issues have been introduced. A complex assembly system can involve many different automation types but studies show that $95 \%$ of the tasks are performed by hand by the operator's own experience [2]. The most common task for operators in final assembly are pick-and-place tasks, which could easily be replaced by co-bots [8] in order to improve the work environment for operators. Results from case studies shows that at perceived complex workstations, work variance was the main cause of complexity (36 stations at 7 companies, Mattsson, et al. [9]). Work variance was in the study connected to cognitive load e.g. that there are many product variants, many other tasks to perform except for the assembly tasks and that it takes time to learn the station work. The results indicate that how product variants and instructions are presented play an important role in how assembly is perceived by operators. To support operators' in a better the way instructions and information are presented could be improved to support them [10-16].

The aim of this paper is to present a review of the development of Human-Automation Interaction in order to see the trends of interaction between humans and automation and not specifically the technology used. This will be used in order to suggest cognitive automation strategies to support operator 4.0 and to find solutions that could increase operators' performance and satisfaction in a final assembly context.

Formulating strategies form cognitive automation is becoming more and more important since the complexity of the work environment increases. Findings from the literature review described in this paper shows that there is a gap within the research of measuring how the operators perceives this complex environment and what factors to measure to capture this. A lot of the research done within HAI is in the environment of controlrooms and air-traffic control, but there is not a lot done within the area of manufacturing and production. Technologies and automation has been in focus the resent years but it is seen that research within interaction and human factors is needed to fully understand the potential of HAI.

\section{Definition of HAI}

Although HAI has been approached from many perspectives the effects of interaction are still hard to predict [17-23]. In HAI there are often conflicting factors; for instance demands to increase the quality and decrease the time, while at the same time maintaining sufficiently satisfied workers e.g. increasing both technological and social conditions [24,25]. At a complex assembly station the operator is affected by several similar or 
different tools, that he or she controls and receives information from i.e., there are many factors affecting the interactions. Wickens, et al. [26] states that when designing for effective HAI (safer, more satisfactory and less disruptive) that appropriate feedback is important to show the status of the automation processes (system process). The feedback could be multimodal in order to not overload the operators' cognitive senses. The authors mention the relevance of appropriate $L O A$ and the importance of trust i.e. these factors are still central. Other authors also empathize trust [27]. Human-Automation Interaction (HAI) can be defined as the way a human is affected by, controls and receives information from automation [28], while performing a task. An example of this is an operator in final assembly, using an automatic tool to mount a generator on an engine. The operator is affected by how the tool is constructed, by for instance its weight. He or she controls the tool and is given information in terms of vibration and a pre-set draw while performing the assembly task.

\section{Trends within technologies and automation}

Trends towards collaborative work places and high level of automation is still not applied in final assembly in a bigger extend $[8,29]$ because of the need for high flexibility and a high level of complexity. Manufacturing complexity [30] can be defined as a combination of product variants, work content, layout, tools and support tools and work instructions, this complexity is often the highest in final assembly. Managing this complexity includes successfully managing the interactions between humans and technology [31] and improving the operator performance i.e. to decrease process errors, achieve high quality, achieve good working conditions, fast processes, and quick change-overs and to decrease cost $[3,32,33]$. In order to manage the complexity and improve the operators performance and thereby the productivity of the whole system, cognitive ergonomics needs to be considered by implementing cognitive automation solutions [34].

Today there are a lot of technologies available on the market in terms of tablets, glasses, Augmented Reality (AR), Virtual Reality (VR) etc. that could support the operator but there is not a lot of research on how the operator perceive these solutions and how the support the operators cognitive processes. The development of the tools must go from technology centred to human centred design in order to fit the capability of the operators [6]. Most research on cognitive automation in manufacturing systems focuses on parameters such as time, cost, flexibility and quality in manual tasks [34] and safety and collaboration in more automated tasks [35] not on operators' cognitive situation. One important challenge connected to this is to handle demands regarding social sustainability that makes it important to be attractive to a workforce with varying age, skills and health issues [36]. Handling this is connected to improving the operator performance that is to decrease process errors, achieve high quality, achieve good working conditions, fast processes, quick change-over's, and, to decrease cost $[37,38]$. During recent years much has been written in the Human-Automation Interaction area and especially focus have been on the area of autonomous cars. The focus connects to safety and control issues due to that the driver is not in the loop i.e. is not active in the decisionmaking and cannot take over the driving if the automation fails [39-41]. Complex interactions have therefore been investigated

in terms of adaptive automation and decision-making [42-44]. Similarly much research is carried out to further understand the conflicting scenarios that can arise when a pilot does not see what the autopilot is doing (exemplifying the importance of visualising the system process of the automation) $[45,46]$.

The evolution of digital tools $[47,48]$, increased number of co-bots [8] and human-robot collaboration [49,50] in final assembly points towards an increased use of both cognitive and physical automation in the final assembly context. HAI will be more and more common and the need for structure and measure parameters related to HAI will be essential $[19,51,52]$. In the concept of operator 4.0 a smart and skilled operator performs 'work aided' by machines if and as needed. It represents a new design and engineering philosophy for adaptive production systems where the focus is on treating automation as a further enhancement of the human's cognitive capabilities [53].

\section{Methodology}

The methodology for the literature review and the future suggestions of improvement will be based on the five-stage grounded-theory method for reviewing the literature in an area, illustrated in table 1 [54].

\section{Step 1 - Define}

\section{Define inclusion criteria}

Year of publication: two time span has been collected; the first is from 2000-2010 and the other from 2011, because number of citations differs and we wanted the latest research within the field in order to see trends. We know that there is a lot being done in the 1960, 1980 for example, but we choose to focus on 2000 and forward in our review because the rapid evolution of IoT, AR, Collaborative Robots etc.

Type of article: Review based journal papers from different

Table 1: The five-stage grounded theory methods used for literature review.

\begin{tabular}{|l|l|}
\hline $\mathbf{1}$ & DEFINE \\
\hline 1.1 & Define the criteria for inclusion \\
\hline 1.2 & Identify the fields of research \\
\hline 1.4 & Determine the appropriate source \\
\hline $\mathbf{2}$ & Decide the specific search terms \\
\hline 2.1 & SEARCH \\
\hline $\mathbf{3}$ & Search \\
\hline 3.1 & SELECT \\
\hline $\mathbf{4}$ & Refine the sample \\
\hline 4.1 & ANALYZE \\
\hline 4.2 & Open coding \\
\hline 4.3 & Axial coding \\
\hline $\mathbf{5}$ & Selective Coding \\
\hline 5.1 & PRESENT \\
\hline 5.2 & Represent and structure the content \\
\hline & Structure the article \\
\hline
\end{tabular}


journals and publicists is the main collection criteria. This is seen as a quality check to have the highest quality paper included in the review. Due to the second time span the inclusion criteria was expanded to also include conference papers books and reports (Journal 84\%/conference 9\%/ book 4\% report 3\%). Furthermore, if the paper are theoretical, case studies, experimental etc. is not seen as an exclusion criteria.

Citations: There are different criteria depending on the time span. Higher number of citations $>80$ for the articles before 2011 and $>5$ for the articles in the second time span.

Identify the fields of research: A lot of the HAI research is done within computer science or AI so the collection tries to be as broad as possible including as many research fields as possible.

Determine appropriate sources: The first search on google on Human automation interaction, gave over one million hits so the topic is clearly written about, a lot of the hits were not scientific so for the literature review a database collection were made as a first step in order to find scientific papers. Since the area of production is seen as an applied research field it is hard to choose the more theoretical data-bases such as web of science, nor a data base were the author has too much freedom to add papers themselves, such as Scopus. Therefore, two different databases were chosen; one broader and one more specific scientific database were collected: Google Scholar and Science Direct.

Decide on the specific search term(s): "Human-Automation Interaction" AND "complexity", "Human-Automation Interaction" AND "complexity" AND "production systems".

\section{Step 2 and Step 3-Search and Select}

The search process is illustrated in Figure 1.This process has been done in to different stages and time span. Stage 1 included articles from 2000-2010 and comprised 40 Google scholar (586 papers found) and 29 science direct articles (29 papers found) [55].

Stage 2 included articles written 2011-2014 where 40 Google scholar (366 papers found) and 23 science direct articles (23 found). The sample was captured this way to find the most cited articles from 2000-2010 and from 2011-2014. In total 25 papers were removed from the sample due to that they were doubles (56\%), too extensive $(32 \%)$ or due to that they did not fit the scope of investigation (12\%). The key words were chosen this way because an expectation of a wider scope of articles due to research fields in the first search and a more specific production related scope in the second search.

Type of article stated if it was a case study, experiment, literature study or a theoretical paper. The result in figure 2 shows that there are a lot of different types of papers within this research area.

Figure 3 shows that this is a complex topic that is included in many research areas and research fields. The research area was found by studying the introduction or the keywords. 77 explicitly stated areas were found (4 papers had more than one area connected to it). Type of field was added to further state what type of field the article addressed; 88 fields were found

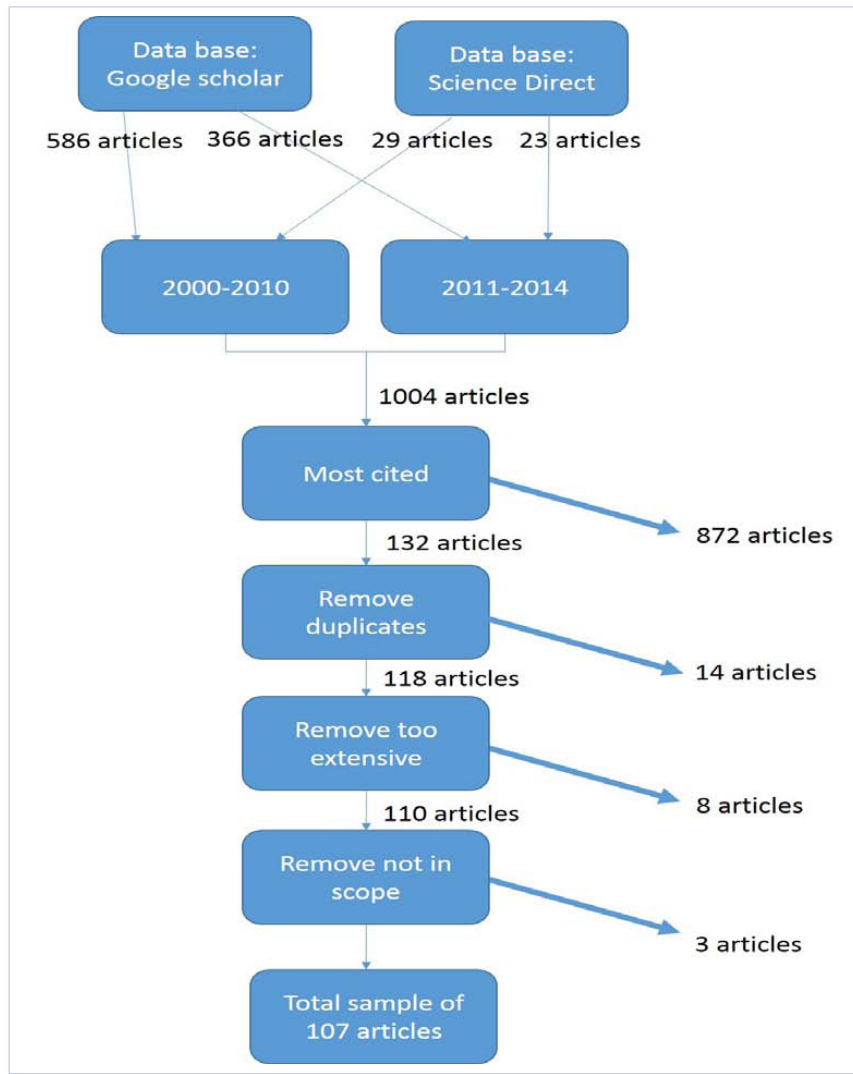

Figure 1: Search process.

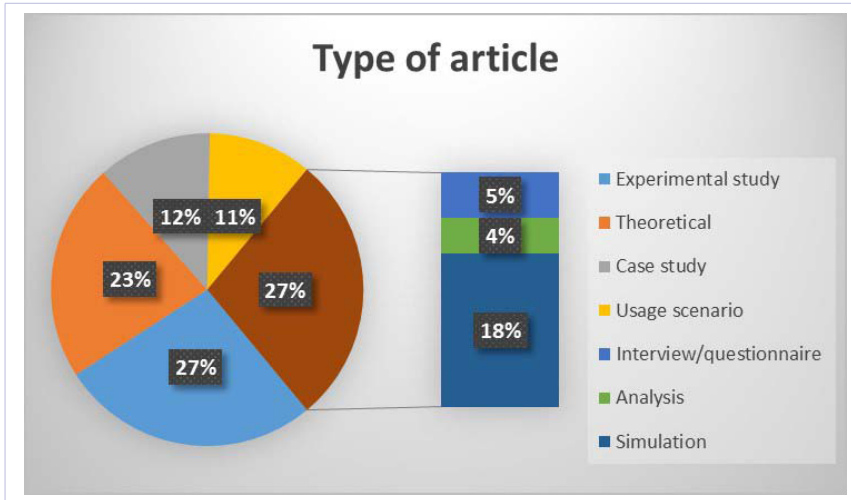

Figure 2: Type of article.

(29 papers had no explicit field connected to it or the field was represented by fewer than 2 papers).

\section{Summary of STEP 1-3}

The result of step 1-3 was a sample of 107 articles books and reports, relevant for research within the area of HAI. Step 1 also shows that the area of Human- Automation-interaction is a very complex area were a lot of research area and fields are involved. One reflection is to also search for highly ranked conference papers in the communities of IEEE, CIRP and IFAC in order to find more relevant research of this type also the papers not highest ranked should be kept track on to see if the will be of interest. 


\begin{tabular}{|c|c|c|c|}
\hline Research Area & [\%] & Research Field & [\%] \\
\hline Human-Automation Interaction & 43 & Aeronautics/Air Traffic Control & 39 \\
\hline Adaptive Automation & 16 & Nuclear & 13 \\
\hline Human-Machine Interaction & 12 & Supervisory control & 11 \\
\hline Human-Robot Interaction & 12 & Military & 9 \\
\hline Human-Centred Automation & 5 & Automotive & 8 \\
\hline Human-Computer Interaction & 5 & Interface & 7 \\
\hline Cognitive Engineering / cognitive systems & 5 & Software, Medicine health and & 5 \\
\hline Human-System Interaction & 3 & Formal verification & \\
\hline
\end{tabular}

Figure 3: Research area and research field.

Furthermore, it is important to see how these theories could be applicable within the area of production for further research.

\section{Step 4 - Analyze}

Each paper was coded into main categories i.e. Humancentered, Automation-centered or Interaction centered based on literature study Mattsson, et al. [56].

- The Human centered category incorporates factors used to study or describe human factors.

- The Automation centered category represents performance indicators used to describe automation systems for instance performance, error/failure management, cost/economy, changes etc. From a production perspective factors connected to performance and automation are very important since they represent the way the system is described in terms of its productivity, efficiency and flexibility.

- The Interaction centered category represents factors that are connected to the joint system of human-automation.

In total 690 sub categories were found. Most sub-categories were found in the Human centred $(\mathrm{N}=260)$ and Automation centred category $(\mathrm{N}=240)$ and fewer were found in the Interaction centred $(\mathrm{N}=187)$ category. The sub-categories captured a wide range of fields, research areas and types of studies and could be seen to reflect recent HAI research. Some authors were represented more than others, which could have skewed the result. For instance the aeronautics field was represented by many similar authors. In aeronautics Levels of Automation is an important focus and also much focus lies in cognitive tasks and situation awareness. Independent of this, the issue of understanding complex tasks for supervisory control or for solving more cognitively demanding tasks is not yet solved. Also it is recognized that the sample cannot account for the full view of the interaction between humans and automation but that the structure performed is a first step towards a framework that can help design future complex systems. The most frequent subcategories (represented more than seven times in articles) are presented in Table 2.

In a production context performance, LoA, safety, reliability, control, function allocation and flexibility are common factors but mental workload, situation awareness, decision-making and trust are not among the most common studied factors. This indicates that more research is needed in the production area, and especially in complex assembly. This gap was also indicated in Mattsson, et al. [57] where it was indicated that operators working at complex stations need better cognitive support to reduce cognitive load.

The final step in the analysis is to put the sub-categories into a system context, also done in Mattsson, et al. [56]). One way to describe the system is by using the black box theory [58], with stimuli - black box - response. In this context, the stimuli could be described as existing conditions that could be changed i.e. design conditions. Examples of sub-categories are; levels of automation, layout, level of flexibility, operator skill, operational structure etc. These are the changeable parameters in the cognitive automation strategy. Inside the black box are the operators' cognitive processes i.e. the mental processes in which humans become aware of and process information [59]. The insight of the black box is often described as very hard to describe, cognitive processes is even harder to describe sine every human thinks in different ways but there are several studies that has been done regarding opening the black box of cognitive theory $[60,61]$ but not in a production context.

The response or output in a production context are the operators' performance with help of the input transformed within the black box into design results. Examples of sub-categories are quality, workload, trust in automation etc.

In Table 3 the number of factors in total and times in articles in total were divided according to key category and black box theory. By dividing sub-categories both according to categories and black box elements it was possible to see indications of both were much research have been focused and where more research is needed in order to formulate a cognitive automation strategy to support the operators' cognitive processes.

The most interesting finding seen from a gap analysis is where there exist fewer (below average) sub-categories in total or per times represented in articles. The Human input

Table 2: Most frequent sub-categories categorized according to key category.

\begin{tabular}{|c|c|c|}
\hline Category & $\begin{array}{l}\text { Most frequent } \\
\text { subcategories }\end{array}$ & $\begin{array}{l}\text { Represented in number } \\
\text { of papers }\end{array}$ \\
\hline \multirow{4}{*}{$\begin{array}{l}\text { Automation- } \\
\text { centred }\end{array}$} & Performance(operational) & 40 \\
\hline & $\operatorname{LoA}^{*}$ & 29 \\
\hline & function allocation & 10 \\
\hline & flexibility & 7 \\
\hline \multirow{5}{*}{$\begin{array}{l}\text { Human- } \\
\text { centred }\end{array}$} & trust/automation reliance & 38 \\
\hline & mental workload & 24 \\
\hline & SA & 21 \\
\hline & decision making & 18 \\
\hline & human errors & 9 \\
\hline \multirow{3}{*}{$\begin{array}{l}\text { Interaction- } \\
\text { centred }\end{array}$} & safety & 15 \\
\hline & control & 11 \\
\hline & design & 7 \\
\hline
\end{tabular}


Table 3: Categorization of most frequent sub-categories into black box areas.

\begin{tabular}{|l|l|l|l|l|l|l|l|l|l|}
\hline \multicolumn{1}{|c|}{ Key category } & \multicolumn{2}{|c|}{ Input to the system } & \multicolumn{2}{c|}{ Black box } & \multicolumn{2}{c|}{ Output from system } & \multicolumn{1}{c|}{ Average per } \\
\hline & Design & conditions & Cognitive & processes & Design & results & key & category \\
\hline & $\begin{array}{l}\text { Number } \\
\text { of sub- } \\
\text { categories } \\
\text { (total) }\end{array}$ & $\begin{array}{l}\text { Number } \\
\text { of times in } \\
\text { articles (total) }\end{array}$ & $\begin{array}{l}\text { Number } \\
\text { of sub- } \\
\text { categories } \\
\text { (total) }\end{array}$ & $\begin{array}{l}\text { Number } \\
\text { of times in } \\
\text { articles (total) }\end{array}$ & $\begin{array}{l}\text { Number } \\
\text { of sub- } \\
\text { categories } \\
\text { (total) }\end{array}$ & $\begin{array}{l}\text { Number } \\
\text { of times in } \\
\text { articles (total) }\end{array}$ & $\begin{array}{l}\text { Number } \\
\text { of sub- } \\
\text { categories } \\
\text { (total) }\end{array}$ & $\begin{array}{l}\text { Number } \\
\text { of times in } \\
\text { articles (total) }\end{array}$ \\
\hline Human & 4 & 50 & 9 & 63 & 8 & 93 & $7(21)$ & $69(206)$ \\
\hline Automation & 11 & 83 & 5 & 12 & 10 & 79 & $9(26)$ & $58(174)$ \\
\hline Interaction & 7 & 33 & 6 & 42 & 10 & 40 & $8(23)$ & $38(117)$ \\
\hline $\begin{array}{l}\text { Total number of sub- } \\
\text { categories in black } \\
\text { box }\end{array}$ & 22 & 166 & 20 & 117 & 28 & 212 & & \\
\hline
\end{tabular}

factors were few (below average number of factors and times represented in papers) which could be due to that the research of Human output factors are well represented. Another explanation is that it might be difficult to characterize a Human input factor. The analysis done in this paper includes the central factors Trust, work environment, observability and social aspects (some of them were also ca sub-categories theorized as output factors). There are however other factors that from a demographics or social sustainability point of view could be seen as Human input factors. One example is individual differences such as height and sight differences, which could cause differences in the perceived complexity. This was seen at a case study were a station was seen complex due to that operators were below average in physical size [62]. The operator in the interview stated that he didn't have a problem with the station since he was taller than average but that other stations more fitted for smaller operators could be troublesome. Another case study have also showed that differences in experience levels and roles (additional tasks except for assembly work) affect the perceived complexity [63]. Performance shaping factors also include eye-sight, time of day, fatigue etcetera [59].

Also Automation within cognitive processes were few. The analysis included the following sub-categories: fault diagnosis (diversity), planning, procedures and system behaviour. To be able to monitor the automation's system processes could be important in order for the operator to better stay in the loop.

\section{Step 5 - Cognitive Automation Strategies for Final} Assembly

There is a lack of strategies and methods to support cognitive automation strategies [64] but it is well needed in a complex assembly environment were technical solutions have increased enormous the last five years. Results from the first steps in the review shows that there are many different research areas and research fields within in this area. To create a good cognitive automation strategy; the key issue is not who make the decision or on what level the decisions are made, but why the decisions are made and upon what facts. The automation strategies needs to be addressed by working with teams from different levels and areas within the company. An example of a team is a mixture of operators, production engineers, human-resource, logistics, ergonomics, product development and IT.
The result in table 3 indicates that more research is needed within cognitive processes and foremost automation of cognitive processes i.e. cognitive automation. Furthermore there is also a gap in what design conditions connected to the operators' needs and how these conditions could be measured and changed. By choosing a cognitive automation strategy best adapted to the operator and implementing it according to sociotechnical perspectives it is believed that the complex system will benefit the most e.g. it can handle uncertainties [65-67]. The system could in that sense be adapted to fit the operators' individual characteristics. As stated by Fredrick Winslow Taylor best efficiency could be reached if a person works according to his/her natural abilities [68]. This will benefit both social sustainability challenges as well as the demographical ones. Since one of the upcoming challenges regard handling digitalization, it is important that the system's transparency is increased [69]. This should include increasing situational awareness and communication, which is necessary for a dynamic function allocation to work. This could result in increased performance, control, trust and safety but also a decreased mental workload for the operator in theory. Figure 4 illustrates some solutions that support cognitive processes for the operators.

\section{Input/Design conditions}

Data used as input to the black box that has been evaluated are measuring physiological data of the operators e.g. heart rhythm, EEG, activity, temperature [70]. Furthermore external preferences have also been evaluated such as light, sound and temperature. Results shows that it is possible to measure the operators physiological data, more research is needed in order to sort analyse and present the data in the right way and also to optimise the cognitive automation due to the output of the data. Other important sub-category were trust and levels of automation which could be illustrated as AR and support from expert and also how operators feels when they work in collaborative cells, early evaluations shows a positive attitude towards collaborative workplaces. How the operator perceives their workstations is also in important factor when designing the station [30].

\section{Black box/Cognitive processes}

The cognitive process that has been investigated through experiments are intuition $[71,72]$ but further research is needed to also support reasoning. 


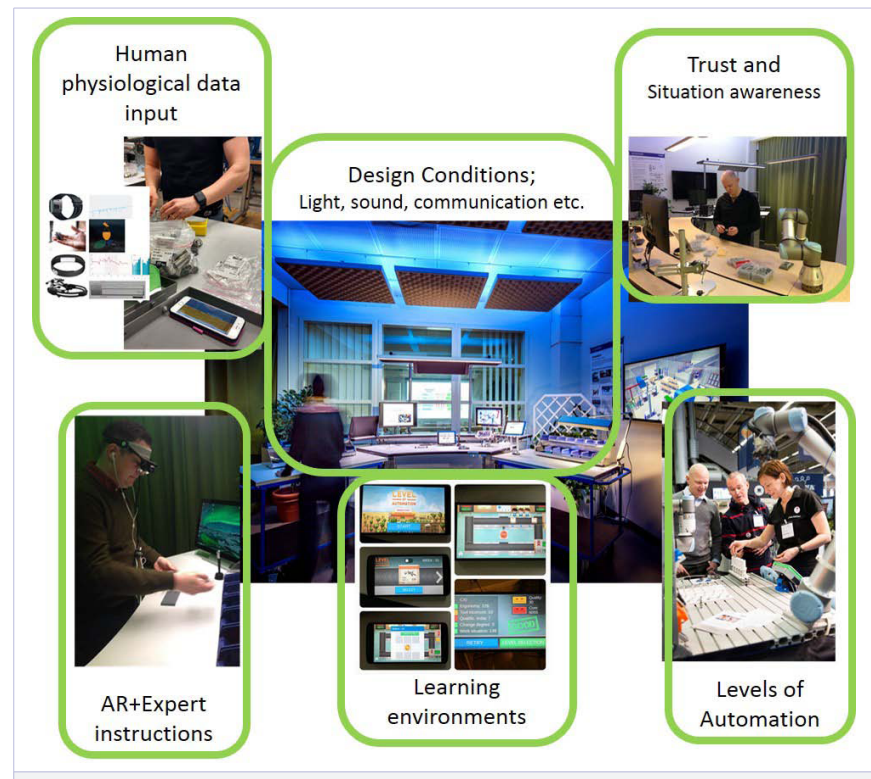

Figure 4: Examples of solution.

\section{Output/Design results}

The most common parameters measured as output are time and quality. It is seen a correlation between cognitive automation, complexity and quality [4].

\section{Conclusion}

The aim of this article was to find the most frequent categories and sub-categories to structure them to support cognitive automation strategies in final assembly. The trends showed that many factors are often used to measure and analyse the HAI effects, which is not applicable to a production context (where it is important that measurements are efficient and precise). The gap found were that more research is needed in what input or design conditions could be directly connected to the operators' cognitive processes. To measures the cognitive processes is also needed and at the same time very hard to do since every human is different. This article shows some solutions that has been tested and evaluated; such as physiological data as input, external design of the assembly station, personalised instructions and collaborative robot cells.

\section{References}

1. Lotter B, Wiendahl HP, ElMaraghy HA. Changeable and Reconfigurable Assembly Systems Changeable and Reconfigurable Manufacturing Systems. 2009;127-142.

2. Fasth A, Stahre J, and Dencker K. Level of automation analysis in manufactoring systems, 2010;233-242.

3. Michalos G, Makris S, Papakostas N, Mourtzis D and Chryssolouris G. Automotive assembly technologies review: challenges and outlook for a flexible and adaptive approach. 2010:2(2);81-91.

4. Fast-Berglund A, Fässberg T, Hellman F, Davidsson A and Stahre J. Relations between complexity, quality and cognitive automation in mixed-model assembly. 2013;32(3):449-455.

5. ElMaraghy H and ElMaraghy W. Smart Adaptable Assembly Systems.
2016;44:4-13.

6. Endsley MR. Designing for situation awareness: An approach to usercentered design: CRC press. 2016;396.

7. Fast-Berglund A, Palmkvist F, Nyqvist P, Ekered S and Akerman M. Evaluating Cobots for Final Assembly. 2016:44;175-180.

8. Tsarouchi P, Spiliotopoulos J, Michalos G, Koukas S, Athanasatos A, Makris S, et al. A Decision Making Framework for Human Robot Collaborative Workplace Generation. 2016: 44;228-232.

9. Mattsson S, Tarrar M and Fast-Berglund Å. Perceived production complexity - understanding more than parts of a system. 2016;60086016.

10. ElMaraghy W, ElMaraghy H, Tomiyama T and Monostori L. Complexity in engineering design and manufacturing. 2012:61(2);793-814.

11. Schleich H, J. S. J and Scavarda LF. Managing Complexity in Automtive Production. 2007.

12. Heilala J and Voho P. Modular Reconfigurable Flexible Final Assembly Systems. 2001:21(1);20-28.

13. Fasth-Berglund $\AA$ and Stahre J. Cognitive automation strategy for reconfigurable and sustainable assembly systems. 2013:33(3);294303.

14. Makris S, Karagiannis P, Koukas S and Matthaiakis AS. Augmented reality system for operator support in human-robot collaborative assembly. 2016:65(1);61-64.

15. Putz M, apakostas N, Pintzos G, Matsas M and Chryssolouris G. Knowledge-enabled Design of Cooperating Robots Assembly Cells. 2014:23;165-170.

16. Billings C. Aviation Automation: The search for a Human-centered approach. 1997; 337-348.

17. Matthias Heesen, Tobias Hesse, Anna Schieben, Claas Brunken, Christian Löper, Johann Kelsch, et al. Interaction design of automatic steering for collision avoidance: challenges and potentials of driver decoupling. 2015:9(1);95-104.

18. Johannes Weyer RDF, Fabian Adelt. Human-machine cooperation in smart cars. An empirical investigation of the loss-of-control thesis. 2015:72;199-208.

19. Dehais F, Peysakhovich V, Scannella S, Fongue J and Gateau, "Automation Surprise" in Aviation: Real-Time Solutions. 2015;25252534.

20. Oliver Straeter MA and Marcus Arenius. Assessing the Complex Interaction and Variations in Human Performance Using Nonmetrical Scaling Methods. 2015;579-598.

21. Banks VA, Stanton NA and Harvey C. Sub-systems on the road to vehicle automation: Hands and feet free but not 'mind' free driving. 2014:62;505-514.

22. Fereidunian A, Lesani H, Zamani MA, Kolarijani MAS, Hassanpour N and Mansouri SS. A complex adaptive system of systems approach to Human-Automation Interaction in smart grid. 2015,888.

23. Pizziola S, Tessiera C and Dehaisb F. Petri net-based modelling of human-automation conflicts in aviation. 2014;57(3):319-31.

24. Mercer J, Homola J, Cabrall C, Martin L, Morey S, Gomez A, et al. Human-automation cooperation for separation assurance in future NextGen environments. 2014.

25. Wickens CD, Hollands JG, Banbury S and Parasuraman R, Designing for Effective Human-Automation Interaction. 2016. 
26.Xu A and Dudek G, OPTIMo: Online Probabilistic Trust Inference Model for Asymmetric Human-Robot Collaborations. 2015;221-228.

27. Sheridan TB and Parasuraman R. Human-Automation Interaction. 2005:1;89-129

28. Sheridan TB. Human centred automation: oxymoron or common sense?. 1995:1.

29. Bustamante EA, Madhavan P, Wickens CD, Parasuraman R, Manzey D, Bahner-Heyne JE, et al. Current Concepts and Trends in HumanAutomation Interaction. 2009.

30. Lee JD. Review of a pivotal Human Factors Article: "Human and Automation: Use, Misuse, Disuse, Abuse”. 2008 Jun;50(3):404-10.

31.Parasuraman R and Riley V. Human and Automation: Use, Misuse, Disuse, Abuse. 1997: 39(2);230-253

32. Merritt SM and Ilgen DR. Not All Trust is Created Equal: Dispositional and History-Based Trust in Human Automation Interaction. 2008 Apr;50(2):194-210.

33. Sarter NB, Woods DD and Billings CE. Automation Surprises. 1997.

34. Prewett MS, Johnson RC, Saboe KN, Elliott LR and Coovert MD Managing workload in human-robot interaction: A review of empirical studies. 2010:26(5);840-856

35. Ropohl G. Society for Philisophy and Technology. 1999:4(3).

36. Hollnagel E. Cognitive ergonomics: it's all in the mind. 1997:40;1170 1182.

37. Fujimoto T, Jürgens U and Shimokawa K. Transforming Automobile Assembly: Experience in Automation and Work Organization. 1997;116.

38. Fast-Berglund Å, Fässberg T, Hellman F, Davidsson A and Stahre J. Relations between complexity, quality and cognitive automation in mixed-model assembly. 2013:32(3);449-455.

39. Brolin A, Thorvald P, Högberg D and Case K. Using mobile information sources to increase productivity and quality. $2010 ; 450-459$.

40. Fässberg T, Fasth $\AA$ and Stahre J. Classification of carrier and content of information. 2012

41. Bäckstrand G, Brolin A, Högberg D and Case K. Supporting Attention in Manual Assembly and its Influence on Quality. 2010.

42. Bäckstrand G, Thorvald P, De Vin L, Högberg D and Case K. The impact of information presentation on work environment and product quality: a case study. 2008

43. Brolin A, Bäckstrand G, Högberg D and Case K. Inadequately Designed Information and its Effects on the Cognitive Workload. 2011.

44. Thorvald P. Presenting Information in Manual Assembly. 2011.

45. Fast-Berglund $\AA$ and Blom E. Evaluating ICT-Tools for Knowledge Sharing and Assembly Support. 2014.

46. Xu LD, He W and Li S. Internet of Things in Industries: A Survey. 2014:10(4);2233-2243.

47. Michalosa G, Makrisa S, Tsarouchia P, Guaschb T, Kontovrakisa D and Chryssolouris G. Design considerations for safe human-robot collaborative workplaces. 2015:37;248-253.
48. Wang XV, Mohammed A and Wang L. Cloud-based Robotic System: Architecture Framework and Deployment Models. 2015.

49. Miller CA and Parasuman R. Beyond Levels of Automation: An Architechture for More Flexible Human-Automation Collaboration. 2003:47(1);182-186.

50. Cuevas HM, Fiore SM, Caldwell BS and Strater L. Augmenting Team Cognition in Human-Automation Teams Performing in Complex Operational Environments. 2007:78(5 Suppl);63-70

51. Romero D, Noran O, Stahre J, Bernus P and Fast-Berglund Å. Towards a Human-Centred Reference Architecture for Next Generation Balanced Automation Systems: Human-Automation Symbiosis. 2015;556-566.

52. Wolfswinkel JF, Furtmueller E and Wilderom CP. Using grounded theory as a method for rigorously reviewing literature. 2013:22(1);4555.

53. Mattsson S, Bligård LO, Fast-Berglund Å and Stahre J. Using Usability to Measure Interaction in Final Assembly. 2013:46(15);64-69.

54. Mattsson S, Fasth Å and Stahre J. Describing Human-Automation Interaction in production. 2012.

55.55. Mattsson S, Karlsson M and Fasth Å. Perceived production complexity - understanding more than parts of a system. 2016: 54(20);6008-6016.

56. Bunge M. A general black box theory. 1963:30(4);346-358.

57. Abrahamsson L, Akselsson R, Albin M, Bohgard M, Eklund J, Ericson M, et al. Work and Technology on Human Terms. 2009.

58. Nersessian NJ. Opening the black box: cognitive science and history of science. 1995:10;194-211.

59. Katz JA. A psychosocial cognitive model of employment status choice. 1992:17;29-37.

60. Mattsson S, and Fast-Berglund Å. How to support intuition in complex assembly?. 2016:50;624-628.

61. Mattsson S, Fasth Å, Dencker K, Gullander P, Stahre J, Karlsson M, et al. Validation of the complexity index method at three manufacturing companies. 2013.

62. Fasth-Berglund $\AA$ and Stahre J. Cognitive automation strategy for reconfigurable and sustainable assembly systems. 2013:33(3);294303

63.Trist E. The evolution of socio-technical systems: A conceptual framework and an action research program. 1981.

64. Hendrick $\mathrm{H}$ and Kleiner B. Macroergonomics: an Introduction to Work System Design. 2001.

65.Trist EL and Bamforth KW. Some Social and Psychological Consequences of the Longwall Method of Coal getting. 1951:4;35.

66. Taylor FW. Principles of Scientific Management. 1911.

67. Helldin T. Transparency for Future Semi-Automated Systems. 2014.

68. Mattsson S, Partini J and Fast-Berglund Å. Evaluating Four Devices that Present Operator Emotions in Real-time. 2016:50;524-528.

69. Mattsson S, Fast-Berglund $\AA$ and Stahre J. Managing Production Complexity by Supporting Cognitive Processes in Final Assembly. 2014;16-18. 